\title{
Preliminary Spectroscopic Measurements for a Gallium Electromagnetic (GEM) Thruster
}

\author{
Robert. E. Thomas ${ }^{1}$, Rodney L. Burton ${ }^{2}$ and Nick G. Glumac ${ }^{3}$ \\ University of Illinois, Urbana, IL, 61801 \\ Kurt A. Polzin ${ }^{4}$ \\ NASA-Marshall Space Flight Center, Huntsville, AL 35812
}

\begin{abstract}
As a propellant option for electromagnetic thrusters, liquid gallium appears to have several advantages relative to other propellants. The merits of using gallium in an electromagnetic thruster (EMT) are discussed and estimates of discharge current levels and mass flow rates yielding efficient operation are given. The gallium atomic weight of $\mathbf{7 0}$ predicts high efficiency in the 1500-2000 s specific impulse range, making it ideal for higherthrust, near-Earth missions. A spatially and temporally broad spectroscopic survey in the 220-520 nm range is used to determine which species are present in the plasma and estimate electron temperature. The spectra show that neutral, singly, and doubly ionized gallium species are present in a $20 \mathrm{~J}, 1.8 \mathrm{kA}$ (peak) arc discharge. With graphite present on the insulator to facilitate breakdown, singly and doubly ionized carbon atoms are also present, and emission is observed from molecular carbon $\left(\mathrm{C}_{2}\right)$ radicals. A determination of the electron temperature was attempted using relative emission line data, and while the spatially and temporally averaged spectra don't fit well to single temperatures, the data and presence of doubly ionized gallium are consistent with distributions in the 1-3 eV range.
\end{abstract}
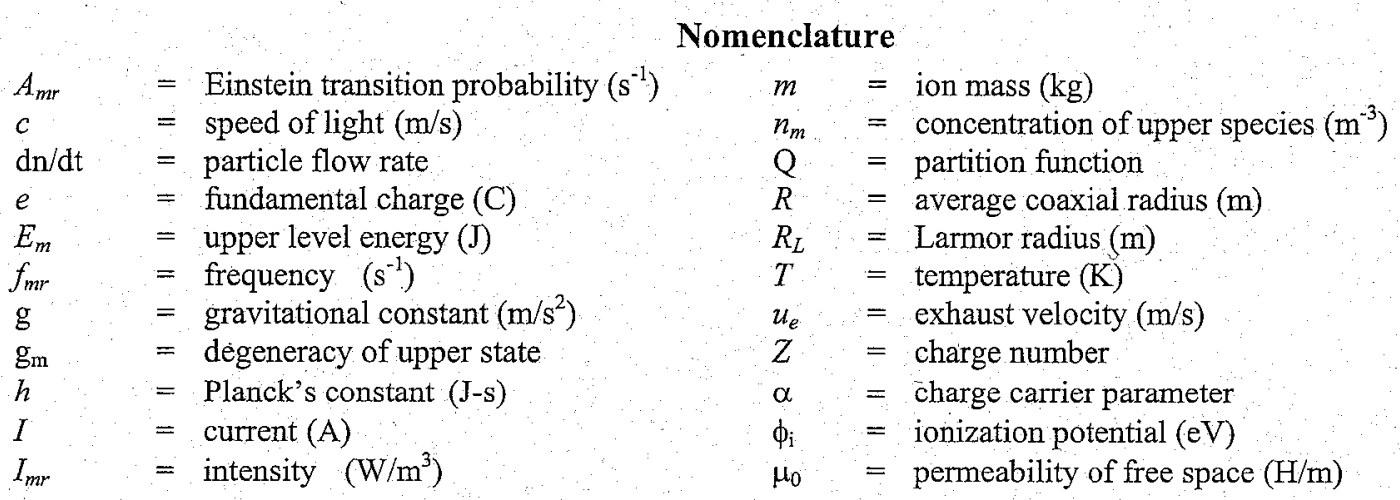

\section{Introduction}

allium as a propellant for high-power electric propulsion appears to have several advantages
presently in use. However, little is known about its properties in the high-current arc dischat
electric propulsion devices. Previously, a two-stage gallium electromagnetic (GEM) thruster design
in which the first stage served as a low-energy pulsed gallium plasma source and the second stage op
power to accelerate the ionized plasma to produce thrust. This was followed by a further study of the
using gallium in EMTs.
${ }^{1}$ Graduate Research Assistant, Department of Aerospace Engineering, Member AIAA
${ }^{2}$ Professor, Department of Aerospace Engineering, Associate Fellow AIAA
${ }^{3}$ Professor, Department of Mechanical Engineering, Member AIAA
${ }^{4}$ Propulsion Research Scientist, Nuclear Systems Branch, Propulsion Systems Dept., Member AIAA 
This paper describes spectroscopic measurements that have been conducted on a pulsed, coaxial plasma injector that is prototypical of the first-stage of a GEM thruster. These spectra were acquired to determine the various particle species produced in a relatively low-energy gallium arc discharge.

In section II we survey the performance of EMTs operating on various propellants and estimate the optimum mass flow rate and discharge current for a gallium EMT based on the scaling of various parameters calculated from the literature data. The experimental setup used for obtaining spectroscopic data in a coaxial gallium plasma source is presented in section III, and the data collected follows in section IV.

\section{Performance Scaling}

\section{A. Survey of Past EMT Performance Data}

Propellant choice strongly affects the operation of EMTs. From the data collected in the MPD and PPT literature, we observe that high efficiency is only achieved when the ionized propellant flow has enough charge carriers to conduct the discharge current. In the absence of sufficient current carriers, severe erosion of the electrodes and insulator occurs. In addition, a second requirement for high-efficiency operation is that the ion Larmor radius is sufficiently small compared to the radius of the thruster. A review of literature data, a sampling of which is shown in Table 1, reveals that both requirements appear to have a significant effect on performance. The experimental data span a wide range of propellant atomic weights, with data on hydrogen ( $A W=1)$, argon ( $A W=40)$, and xenon ( $\mathrm{AW}=131)$ taken from Ref. [3] and data for nitrogen $(\mathrm{AW}=14)$ from Ref. [4]. The last two columns in Table 1 were derived from the literature data to provide quantitative measures of high-efficiency EMT operation.

Table 1. Experimental MPD performance using various propellants, plus calculated parameters $\alpha$ and $R_{\mathrm{L}}$

\begin{tabular}{lcccccccc}
\hline Propellant & $\begin{array}{l}\text { Ion. } \\
\text { Wt. }\end{array}$ & $\begin{array}{l}\text { Discharge } \\
\text { Current, kA }\end{array}$ & $\begin{array}{l}\text { Propellant } \\
\text { Flow, gm/s }\end{array}$ & $\begin{array}{l}\text { Spec. Imp., Eff., } \eta \\
\text { sec }\end{array}$ & $\begin{array}{l}\text { Charge carrier } \\
\text { parameter, } \alpha\end{array}$ & $\begin{array}{l}\text { Larmor } \\
\text { Rad.,cm }\end{array}$ \\
\hline Hydrogen & 1 & 20 & 0.5 & 16000 & 0.52 & 4.80 & 1.3 \\
Nitrogen & 14 & 18 & 4.0 & 4000 & 0.37 & 1.60 & 5.0 \\
Argon & 40 & 20 & 6.0 & 2800 & 0.20 & 0.72 & 8.8 \\
Xenon & 131 & 20 & 6.0 & 1400 & 0.10 & 0.22 & 14.4 \\
Xenon & 131 & 15 & 3.0 & 1600 & 0.09 & 0.15 & 21.9 \\
\hline
\end{tabular}

The charge carrier parameter $\alpha$ is calculated from the particle flow rate $d n / d t$ (mass flow rate $d m / d t$ divided by ion mass $m$ ) and discharge current $I$ :

$$
\alpha=(Z e / m I)(d m / d t)
$$

where $e$ is the fundamental unit of charge and $Z=1$ for singly ionized and 2 for doubly ionized propellant. The ratio defined in $\alpha$ represents the fraction of the discharge current that can be carried by the ionized propellant based on the number of charge carriers present. The calculations of $\alpha$ for each propellant reveal that singly-ionized hydrogen and nitrogen possess enough charge carries to conduct the discharge current $(\alpha>1)$ while argon and xenon do not $(\alpha<1)$. These data also show that $\alpha$ correlates with efficiency, yielding higher efficiencies for increasing values of $\alpha$.

The Larmor radius is defined as $R_{L}=m u_{e} / Z e B$ where $B$ is the magnetic field strength and $u_{e}$ is the particle axial exhaust velocity. Using the discharge parameters in Table 1, we estimate the Larmor radius as:

$$
R_{L}=2 \pi\left(m / Z e \mu_{0} I\right) R u_{e}
$$

where $\mu_{0}$ is the magnetic permeability of free space, and $R$ is taken as the average radius of a coaxial thruster:

$$
R \equiv\left(R_{\text {anode }}+R_{\text {cathode }}\right) / 2 .
$$


We have calculated $R_{L}$ in Table 1 using $R=3 \mathrm{~cm}$, which is consistent with Ref [3] and [4]. For efficient thruster operation, the discharge current and resulting self-induced magnetic field must be high enough to allow ions that are driven radially by the $\mathrm{E}$ field to turn and drift axially out of the thruster without hitting an electrode. This will occur in thrusters where the value of $R_{L} \leq R$, and the data in Table 1 show that higher thrust efficiency is obtained in EMTs when this condition is satisfied.

Summarizing, we contend that efficient operation of EMTs occurs when there are enough charge carriers present to conduct the current and when the Larmor radius is smaller than thruster channel. For heavier propellants, this implies:

- The discharge current must scale with ion mass and exhaust velocity to keep the Larmor radius $R_{\mathrm{L}}$ small. This was not done is previous experiments with xenon, ${ }^{3}$ which should have been operated at higher current levels than argon or nitrogen to achieve high efficiency.

- The propellant mass flow rate must scale with ion mass and discharge current to maintain a high number of charge carriers, i.e. $\alpha>1$. Thrusters using heavier propellants such as xenon and gallium need to be operated at much higher mass flow rates than argon or hydrogen to provide enough current-carrying particles.

\section{B. Predictions for High-Performance using Heavy Propellants}

Using the above approach, we analyze the use of heavy propellants (gallium, xenon, bismuth) in more detail for the purpose of estimating EMT operating conditions that will result in high thrust efficiency. The estimates, summarized in Table 2 along with data from literature, and computed by fixing $\alpha=1.6$ and $R_{L}=R$.

Table 2. EMT operating conditions using different propellants with measured or predicted efficiencies.

\begin{tabular}{lccccccc}
\hline Propellant & $\begin{array}{c}\text { Ion } \\
\text { At. Wt. }\end{array}$ & $\begin{array}{c}\text { Current, } \\
\text { kA }\end{array}$ & $\begin{array}{c}\text { Propellant } \\
\text { Flow, gm/s }\end{array}$ & $\begin{array}{r}\text { Spec. Imp., } \\
\text { sec }\end{array}$ & $\begin{array}{c}\text { Eff. } \\
\eta\end{array}$ & $\begin{array}{c}\text { Charge carrier } \\
\text { parameter, } \alpha\end{array}$ & $\begin{array}{c}\text { Larmor } \\
\text { Rad., cm }\end{array}$ \\
\hline Hydrogen $^{3}$ & 1 & 20 & 0.50 & 16000 & 0.52 & 4.80 & 1.3 \\
Lithium $^{5}$ & 7 & 9 & 0.45 & 4500 & 0.55 & 0.70 & 5.4 \\
Nitrogen $^{4}$ & 14 & 18 & 4 & 4000 & 0.37 & 1.60 & 5.0 \\
Nitrogen $^{4}$ & 14 & 21 & 13 & 2800 & 0.50 & 1.60 & 3.0 \\
Gallium & 70 & 75 & 140 & 2000 & 0.50 & 1.60 & 3.0 \\
Gallium & 70 & 56 & 105 & 1500 & 0.43 & 1.60 & 3.0 \\
Xenon & 131 & 140 & 240 & 2000 & 0.50 & 1.60 & 3.0 \\
Xenon & 131 & 105 & 142 & 1500 & 0.43 & 1.60 & 3.0 \\
Bismuth & 209 & 224 & 624 & 2000 & 0.50 & 1.60 & 3.0 \\
Bismuth & 209 & 168 & 468 & 1500 & 0.43 & 1.60 & 3.0 \\
\hline
\end{tabular}

The relationship between propellant atomic weight, discharge current and specific impulse is demonstrated in Table 2. For high-thrust near-Earth missions using electric propulsion, where shorter transfer times are important, the optimum specific impulse is roughly 1500-2000 seconds. We observe that to maintain appropriate values of $\alpha$ and $R_{L}$, both thruster current and propellant flow rate must increase significantly with the propellant atomic weight. Bismuth and xenon (which work well in electrostatic thrusters because they increase thrust density) can be used in an efficient EMT, but the drawback is that the required discharge current exceeds $100 \mathrm{kA}$. At these current levels internal capacitor and transmission line losses become significant, while the high power level drives the thruster towards short pulse lengths and unsteady flow. Propellant flow rates of up to $600 \mathrm{gm} / \mathrm{s}$, even for only microsecond time scales, can only be achieved using an ablative (as opposed to valved) feed system. In Table 2 for lighter propellants $(\mathrm{N}, \mathrm{Li}, \mathrm{H})$ the $I_{\mathrm{sp}}$ is too high for near-Earth missions, and for heavier propellants (Xe, Bi) the current is too high. If we were to consider lower current levels, the $I_{\mathrm{sp}}$ would then be too low. However, operation on gallium appears possible since can we can achieve an $I_{\mathrm{sp}}$ of $1500-2000 \mathrm{~s}$ at reasonable currents and mass flow rates.

In Table 3 we consider the effect on the discharge current and mass flow rate of having a plasma comprised of either singly and doubly ionized gallium, (we show later that both are observed spectroscopically). To hold $\alpha$ constant in a doubly ionized gallium plasma, $I$ would be reduced by a factor of 2 and the propellant flow lowered

3

American Institute of Aeronautics and Astronautics 
by a factor of 4 relative to a plasma comprised only of $\mathrm{Ga}^{+}$. This also means for a given pulse energy, the pulse length is quadrupled for a doubly-ionized propellant. The effect of ionization on frozen flow efficiency is shown in Table 4. Note that the frozen flow efficiency of $\mathrm{Ga}^{+}$at 2000 seconds is the same as lithium at 6000 seconds, indicating potentially high efficiency for gallium. For $\mathrm{Ga}^{++}$, the frozen flow efficiency at $2000 \mathrm{~s}$ is $85 \%$, but it rises to $90 \%$ at $2500 \mathrm{~s}$.

Table 3. Conditions for efficient EMT operation with singly and doubly ionized gallium propellant.

\begin{tabular}{lccccccc}
\hline Propellant & $\begin{array}{c}\text { Ion } \\
\text { At. Wt. }\end{array}$ & $\begin{array}{c}\text { Current, } \\
\text { kA }\end{array}$ & $\begin{array}{c}\text { Propellant } \\
\text { Flow, gm/s }\end{array}$ & $\begin{array}{c}\text { Spec. Imp., } \\
\text { sec }\end{array}$ & $\begin{array}{c}\text { Eff'cy } \\
\eta(\text { est.) }\end{array}$ & $\begin{array}{c}\text { Charge carrier } \\
\text { parameter, } \alpha\end{array}$ & $\begin{array}{c}\text { Larmor } \\
\text { Radius, cm }\end{array}$ \\
\hline Gallium $^{+}$ & 70 & 75 & 140 & 2000 & 0.50 & 1.60 & 3.0 \\
Gallium $^{+}$ & 70 & 56 & 105 & 1500 & 0.50 & 1.60 & 3.0 \\
Gallium $^{++}$ & 70 & 37 & 35 & 2000 & 0.50 & 1.60 & 3.0 \\
Gallium $^{++}$ & 70 & 28 & 26 & 1500 & 0.50 & 1.60 & 3.0 \\
\hline
\end{tabular}

single ion, ${ }^{++}$double ion

Table 4. Estimated frozen flow efficiency in EMTs operating on gallium and lithium.

\begin{tabular}{lccccc}
\hline Propellant & $\begin{array}{c}\text { Ion } \\
\text { At. Wt. }\end{array}$ & $\begin{array}{c}\text { Spec. Imp., } \\
\text { sec }\end{array}$ & $\begin{array}{c}\text { Kinetic } \\
\text { Energy, eV }\end{array}$ & $\begin{array}{c}\text { Ionization } \\
\text { Energy, eV }\end{array}$ & $\begin{array}{c}\text { Frozen } \\
\text { Flow Eff. * }\end{array}$ \\
\hline Lithium $^{+}$ & 7 & 6000 & 132 & 5.4 & 0.96 \\
Gallium $^{+}$ & 70 & 2000 & 146 & 6.0 & 0.96 \\
Gallium $^{+}$ & 70 & 1500 & 82 & 6.0 & 0.83 \\
Gallium $^{++}$ & 70 & 2500 & 228 & 26.4 & 0.90 \\
Gallium $^{++}$ & 70 & 2000 & 146 & 26.4 & 0.85 \\
Gallium $^{++}$ & 70 & 1500 & 82 & 26.4 & 0.76 \\
\hline
\end{tabular}

${ }^{+}$single ion ${ }^{\text {t+ }}$ double ion *based on ionization energy

The performance estimates allow us to conclude that gallium propellant can achieve efficient operation at an $I_{\mathrm{sp}}$ of 1500-2500 seconds. The current levels and mass flow rates necessary to maintain a small Larmor radius and provide enough charge carriers for the discharge are reasonable and can be achieved in a pulsed EMT.

\section{Experimental Apparatus}

A coaxial pulsed discharge was employed to produce a gallium plasma, which was photographed and spectroscopically interrogated. To our knowledge, our spectroscopic data and photographs represent the first ever obtained using a pulsed gallium plasma discharge. In our setup, a coaxial geometry is used with the outer electrode connected to a $20 \mathrm{~J}, 20 \mathrm{~Hz}(400 \mathrm{~W}) \mathrm{GE} /$ Unison Industries pulser that provides a $12 \mu$ s rise time, non-reversing current pulse with a low inductance circuit containing a free-wheeling diode. Gallium is fed through a sintered tungsten plug, where it is ablated by a pulsed arc with a full width at half max (FWHM) duration of $\sim 50 \mu$ s. The repetition rate is controlled using a pulse generator that can be varied between $0.1 \mathrm{~Hz}$ and $20 \mathrm{~Hz}$. The current and terminal voltage characteristics of the pulsed discharge are shown in Fig. 1. 


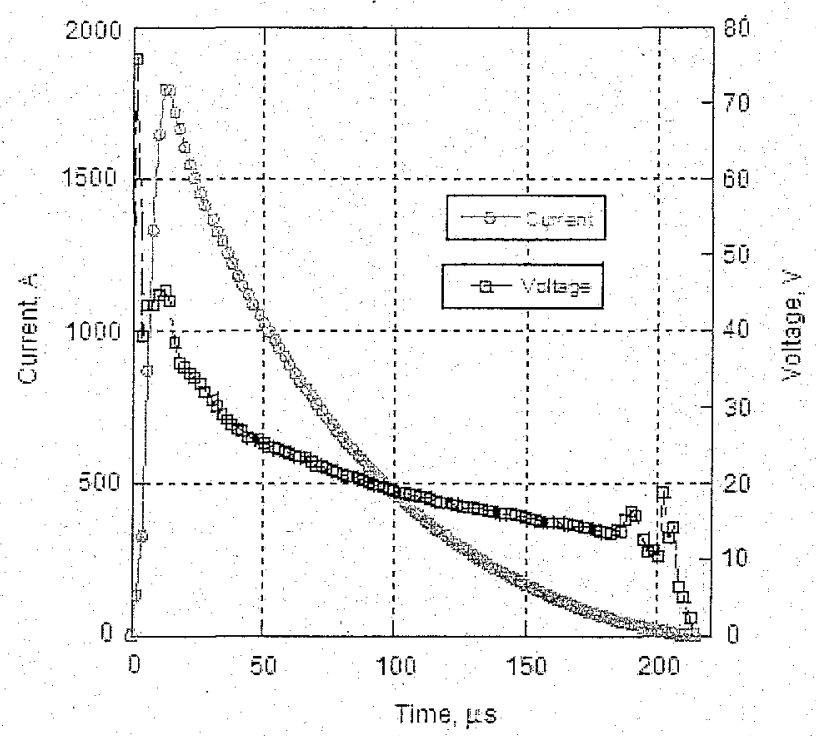

Figure 1. Discharge current and terminal voltage waveforms for a $20 \mathrm{~J}$ pulse.

The coaxial gallium pulsed plasma source is shown in Fig. 2. The stainless steel outer electrode has an outer and inner diameter of $5.72 \mathrm{~cm}(2.25 \mathrm{in})$ and $2.22 \mathrm{~cm}(0.88 \mathrm{in})$, respectively. A boron nitride insulator electrically separates the inner and outer electrode. The inner (grounded) electrode is a $1.91 \mathrm{~cm}(0.75 \mathrm{in}) \mathrm{SS}$ tube press-fitted with a $1.27 \mathrm{~cm}\left(0.5^{\prime \prime}\right)$ porous tungsten disk. During operation, the electrodes are mounted into a 5-way vacuum cross, which is attached to the main vacuum chamber. This arrangement provides three windows for diagnostic optical access. A baffle was inserted into the 5-way cross to prevent ejected gallium particles from reaching the main chamber. Vacuum is maintained by a TPH 15,00 turbomolecular pump, which is backed by two Roots blowers and two Kinney mechanical displacement pumps. A background pressure of $5 \times 10^{-5}$ torr was maintained during testing. A photograph of the gallium discharge is found in Fig. 3. In the right hand panel of Fig. 3 we observe that the discharge appears to be nearly symmetric and extends several $\mathrm{cm}$ from the electrodes.

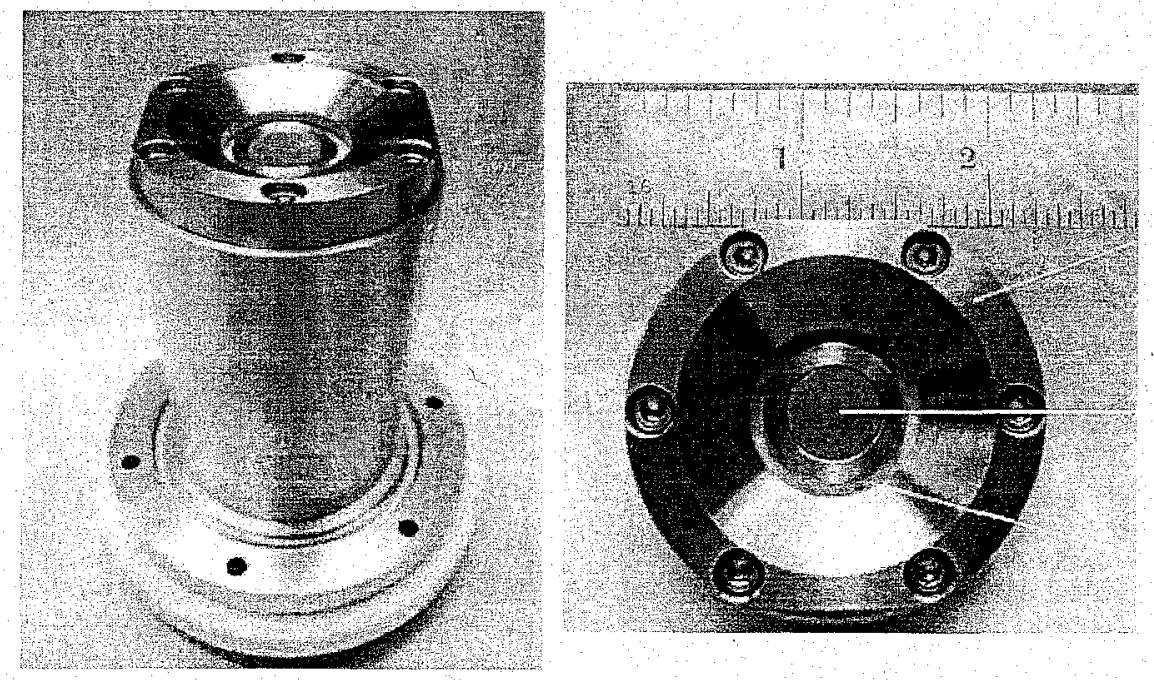

Outer Electrode

Figure 2. Gallium coaxial pulsed plasma source.

Inner Electrode (grounded)

Boron Nitride Insulator 


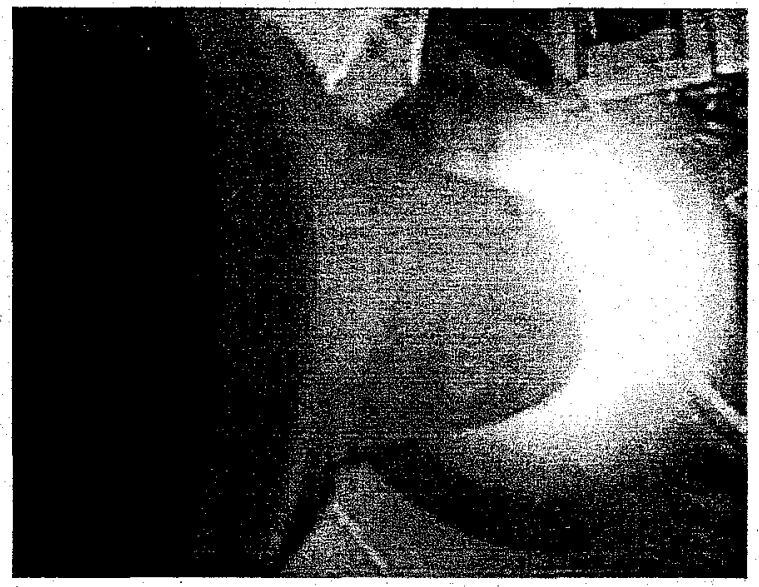

(1) Backview

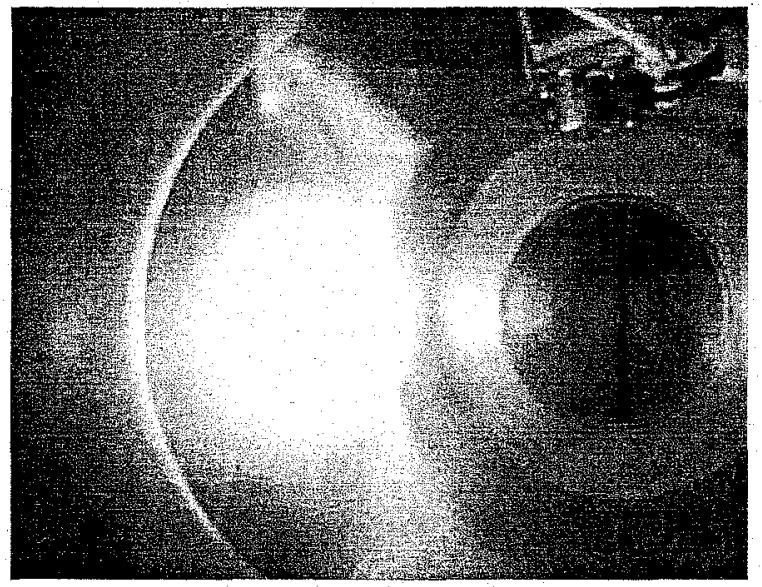

(2) Sideview

Figure 3. Photos of a pulsed gallium plasma discharge.

Two difficulties were initially encountered after firing the $20 \mathrm{~J}$ igniter. The first was that the arc preferentially struck the exposed stainless steel on the inner electrode, as opposed to the gallium. This was verified by examining the terminal voltage trace and through physical inspection of the cathode between firings. To remedy this, selffusing silicone rubber tape was used as an insulator, leaving only metallic gallium exposed. Additionally, it was found that below a pressure of roughly 1 torr, a discharge would not initiate due to the lack of initial charge carriers. This was addressed by bridging the anode and cathode with a thin layer of carbon graphite applied with a spray technique. This technique is commonly employed in vacuum arc thrusters, where the graphite serves as the initial conductive path between the anode and cathode, providing a means for Joule heating at the coating-cathode interface. Neither a trigger electrode nor a specific electrical trigger pulse generator is required; the method has therefore been dubbed "triggerless" arc initiation. 6,7 Using this technique, the gallium plasma source can be operated at a background pressure of $5 \times 10^{-5}$ torr.

\section{Spectroscopic Data}

We acquired spectroscopic data from the discharge to determine which species were present. These spectra were obtained using a $25 \mathrm{~mm}$ focal length spectrometer with 5 micron inlet slit, yielding $0.7 \mathrm{~nm}$ resolution over the range of $220 \mathrm{~nm}$ to $520 \mathrm{~nm}$. Emission was collected using a $12 \mathrm{~mm}$ diameter $\mathrm{f} / 2$ quartz plano convex lens which was focused onto the end of a 400 micron diameter silica fiber. The spectrum was time-integrated over several discharge pulses and spatially integrated over a broad region in which emission was observed. The output of the spectrometer was wavelength-calibrated using a mercury lamp and corrected for relative spectral efficiency using a deuterium lamp. A schematic of the experimental set-up is shown in Fig. 4.

Spectroscopic measurements were obtained at two different vacuum chamber background pressures. The spectrum obtained at a background pressure of 1 torr is shown in Fig. 5. The diameter of the exposed gallium was $12.7 \mathrm{~mm}(0.5 \mathrm{in})$. We observe the presence of neutral gallium as well as singly ( $\left.\mathrm{Ga} \mathrm{II}, \phi_{\mathrm{i}}=6.0 \mathrm{eV}\right)$ and doubly ionized (Ga III, $\phi_{\mathrm{i}}=20.5 \mathrm{eV}$ ) $\mathrm{Ga}$ in the discharge. No significant emissions from other gases are observed, including the silicone rubber tape used as an insulator on the stainless steel. A total of twenty spectral lines were observed: six Ga I lines, five Ga II lines, and nine Ga III lines. Some of these lines are overlapping multiplets and therefore represent averages in intensity and wavelength. Due to the lack of existing Ga III spectroscopic data in the literature, four of these lines are not amenable to any sort of quantitative analysis. The remaining sixteen lines are presented in Table 5. The Ga I data was obtained from Ref [8], while the Ga II and Ga III data were tabulated from various sources. ${ }^{9-12}$. 


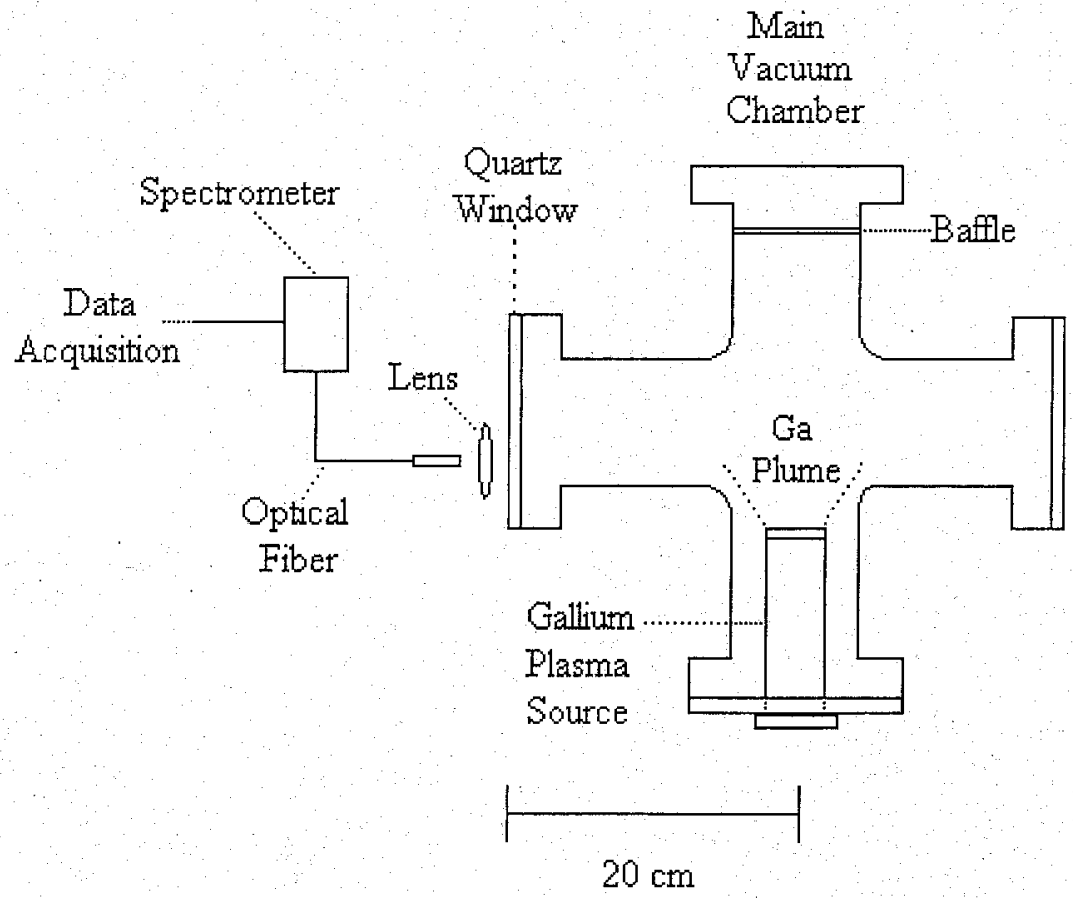

Figure 4. Schematic of the gallium emission spectroscopy setup.

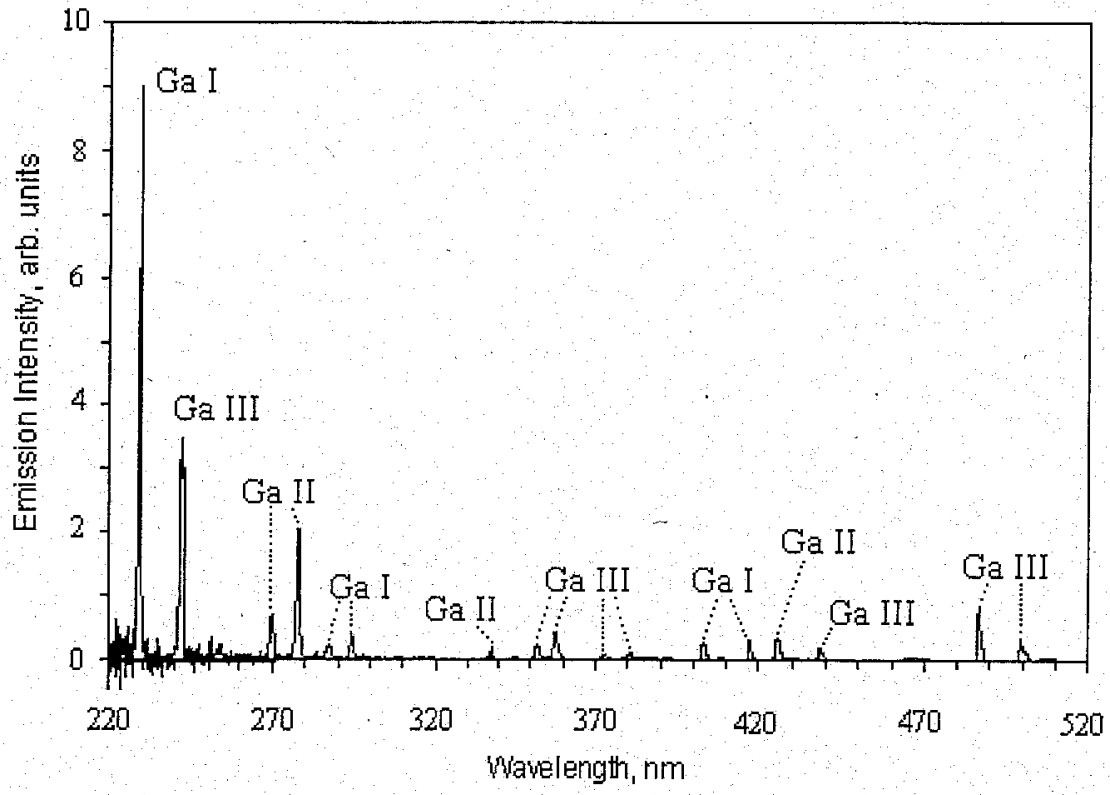

Figure 5. Gallium emission spectrum obtained at a vacuum chamber background pressure of 1 torr. 
Table 5. Gallium neutral and ion species present in a low-energy arc discharge.

\begin{tabular}{ccccccc}
\hline Specie & $\begin{array}{c}\text { Emission } \\
\text { Line }(\mathbf{n m})\end{array}$ & $\begin{array}{c}\text { Upper Level } \\
\text { Energy, cm }\end{array}$ & $\begin{array}{c}\text { Lower } \\
\text { Level }\end{array}$ & $\begin{array}{c}\text { Upper } \\
\text { Level }\end{array}$ & $\begin{array}{c}\text { Upper Level } \\
\text { Degeneracy }\end{array}$ & $\mathbf{A}_{\text {mr }}\left(\mathrm{s}^{-1}\right)$ \\
\hline Ga I & 229.419 & 43574.91 & $4 \mathrm{p}^{2} \mathrm{P}_{1 / 2}$ & $6 \mathrm{~d}^{2} \mathrm{D}_{3 / 2}$ & 4 & $7.0 \times 10^{6}$ \\
Ga I & 229.787 & 43505.15 & $4 \mathrm{p}^{2} \mathrm{P}_{3 / 2}$ & $8 \mathrm{~s}^{2} \mathrm{~S}_{1 / 2}$ & 2 & $5.8 \times 10^{6}$ \\
Ga I & 287.424 & 34781.66 & $4 \mathrm{p}^{2} \mathrm{P}_{1 / 2}$ & $4 \mathrm{~d}^{2} \mathrm{D}_{3 / 2}$ & 4 & $1.2 \times 10^{8}$ \\
Ga I & 294.364 & 34787.85 & $4 \mathrm{p}^{2} \mathrm{P}_{3 / 2}$ & $4 \mathrm{~d}^{2} \mathrm{D}_{5 / 2}$ & 6 & $1.3 \times 10^{8}$ \\
Ga I & 294.417 & 34781.66 & $4 \mathrm{p}^{2} \mathrm{P}_{3 / 2}$ & $4 \mathrm{~d}^{2} \mathrm{D}_{3 / 2}$ & 4 & $2.6 \times 10^{7}$ \\
Ga I & 403.299 & 24788.53 & $4 \mathrm{p}^{2} \mathrm{P}_{1 / 2}$ & $5 \mathrm{~s}^{2} \mathrm{~S}_{1 / 2}$ & 2 & $4.9 \times 10^{7}$ \\
Ga I & 417.204 & 24788.53 & $4 \mathrm{p}^{2} \mathrm{P}_{3 / 2}$ & $5 \mathrm{~s} 2 \mathrm{~S}_{1 / 2}$ & 2 & $9.5 \times 10^{7}$ \\
Ga II & 270.047 & 107720.56 & $4 \mathrm{p}^{1} \mathrm{P}_{1}$ & $\mathrm{p}^{2} \mathrm{D}_{2}$ & 5 & $2.3 \times 10^{7}$ \\
Ga II & 277.998 & 135639.24 & $4 \mathrm{p}^{1} \mathrm{P}_{1}$ & $5 \mathrm{~s}^{1} \mathrm{~S}_{0}$ & 1 & $3.9 \times 10^{8}$ \\
Ga II & 337.494 & 137342.44 & $\mathrm{p}^{2} \mathrm{D}_{2}$ & $4 \mathrm{f}^{1} \mathrm{~F}_{3}$ & 7 & $1.9 \times 10^{8}$ \\
Ga II & 337.595 & 137333.33 & $\mathrm{p}^{2} \mathrm{D}_{2}$ & $4 \mathrm{f}^{3} \mathrm{~F}_{3}$ & 7 & $2.0 \times 10^{7}$ \\
Ga II & 426.200 & 137339.64 & $4 \mathrm{~d}^{3} \mathrm{D}_{3}$ & $4 \mathrm{f}^{3} \mathrm{~F}_{4}$ & 9 & $1.7 \times 10^{8}$ \\
& & & & & & \\
Ga III & 241.770 & 185432.59 & $4 \mathrm{~d}^{2} \mathrm{D}_{3 / 2}$ & $4 \mathrm{f}^{2} \mathrm{~F}_{5 / 2}$ & 6 & $9.4 \times 10^{8}$ \\
Ga III & 373.110 & 187566.51 & $5 \mathrm{p}^{2} \mathrm{P}_{1 / 2}$ & $6 \mathrm{~s}^{2} \mathrm{~S}_{1 / 2}$ & 2 & $6.3 \times 10^{8}$ \\
Ga III & 380.660 & 187566.51 & $5 \mathrm{p}{ }^{2} \mathrm{P}_{3 / 2}$ & $6 \mathrm{~s}^{2} \mathrm{~S}_{1 / 2}$ & 2 & $8.3 \times 10^{8}$ \\
Ga III & 499.378 & 160765.56 & $5 \mathrm{~s}^{2} \mathrm{~S}_{1 / 2}$ & $5 \mathrm{p}^{2} \mathrm{P}_{1 / 2}$ & 2 & $2.3 \times 10^{8}$ \\
\hline
\end{tabular}

Experiments conducted at a background pressure of $5 \times 10^{-5}$ torr and performed using a graphite layer between the electrodes to facilitate discharge initiation are shown in Fig. 6. During these tests, the diameter of the exposed gallium was reduced from $12.7 \mathrm{~mm}$ to $5 \mathrm{~mm}$ using silicone tape. Approximately 0.2 grams of graphite bridged the two electrodes, which allowed the pulser to be fired $\sim 120$ times before the graphite was expended.

A comparison between Figs. 5 and 6 allow us to make some interesting observations. When the graphite layer is employed at lower background pressure, the peak intensities of the Ga lines are reduced and there are significant emissions from molecular carbon radicals above $430 \mathrm{~nm}$ (the so-called Swan bands ${ }^{13}$ ). This implies that energy. directed into the production of gallium ions in Fig. 5 is shifted into the production of carbon ions and the excitation of molecular carbon states in Fig. 6.

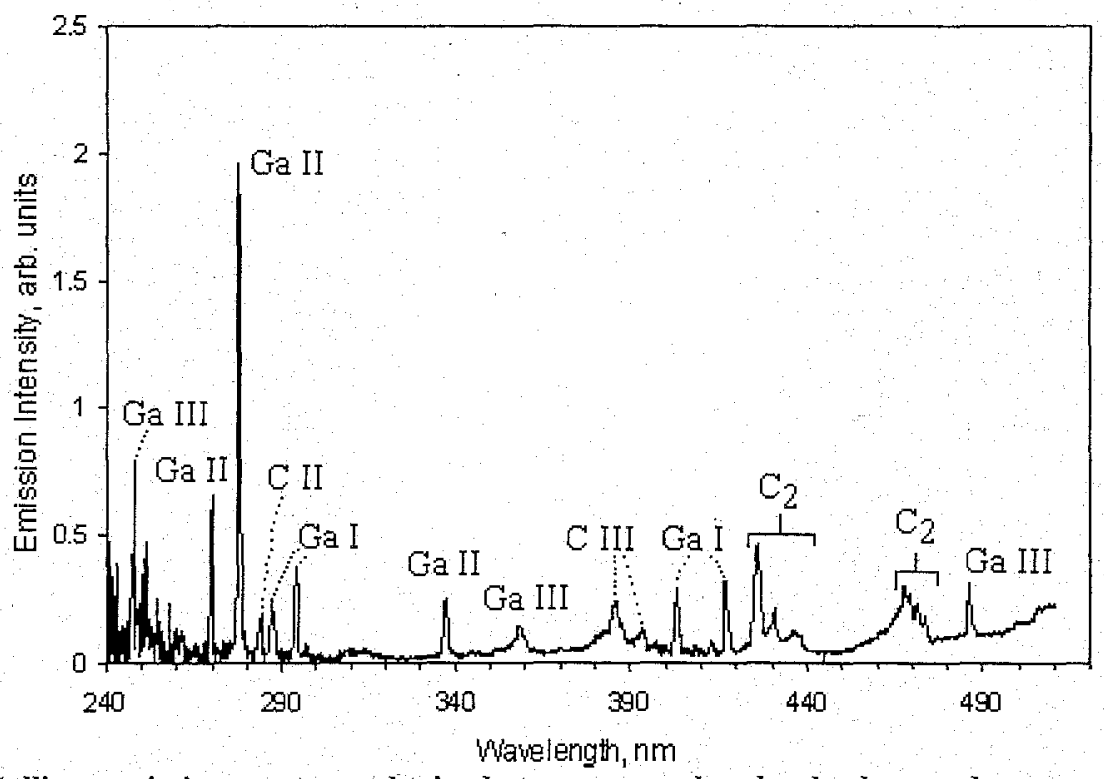

Figure 6. Gallium emission spectrum obtained at a vacuum chamber background pressure of $5 \times 10^{-5}$ torr and employing a graphite layer to facilitate the breakdown process. 
The concentration of each species is related to the emission intensity through the relation ${ }^{14}$

$$
I_{m r}=n_{m} A_{m r} h f_{m r}
$$

where $m$ and $r$ are the upper and lower states of a transition, respectively, $I_{m r}$ is the intensity, $A_{m r}$ is the Einstein transition probability, $h$ is Plank's constant, $f_{m r}$ is the frequency, and $n_{m}$ is the concentration of particles in the upper level. A quantitative spectroscopic analysis may be performed more readily under the conditions of local thermodynamic equilibrium (LTE). Under the conditions of LTE, a single temperature describes the various energy distributions: electron velocity distribution, degree of ionization, and the distribution of excited states. ${ }^{15}$ The relevant temperature is that which describes the distribution function of the species dominating the reaction rates, which in dense laboratory plasmas is the electron temperature. ${ }^{16}$ A check for the existence of LTE can be made by using the Boltzmann relation ${ }^{14}$ :

$$
\ln \left(\frac{I_{m r}}{g_{m} A_{m r} f_{m r}}\right)=\ln \left(\frac{n}{Q}\right)-\frac{E_{m}}{k T}
$$

where $k$ is the Boltzmann constant, $E_{m}$ and $g_{m}$ are the upper state energy and degeneracy, respectively, $Q$ is the partition function, and $T_{\mathrm{e}}$ is the electron temperature. If the data points are sufficiently linear (i.e., follow LTE), the electron temperature can be found by plotting the quantity on the left hand side vs. the upper level energy. The slope of the resulting line has a slope of $-1 / k T_{e}$. A plot of Eq. 5 for the Ga I ( 7 points), Ga II ( 5 points) and Ga III (4 points) lines is shown in Fig. 7 for the background pressure of 1 Torr. Several approximations were necessary to include the three sets of overlapping lines. The relative emission intensity of each line $I_{m r}$ was found by numerical integration of the spectral line width, and for the case of multiplets, the integrated intensity can be decomposed as the sum of two lines, e.g.:

$$
I_{m r}=I_{294.417}+I_{294.424}
$$

An additional relation is needed to 'resolve' the two lines. In order to include the overlapping $294.417 \mathrm{~nm}$ and 294 . $424 \mathrm{~nm}$ lines, the following approximation was used: ${ }^{17}$

$$
\frac{I_{294.417}}{I_{287.424}} \approx \frac{(g A f)_{294.417}}{(g A f)_{287.424}}
$$

The 287.424 line was used because it shares an upper state with the 294.417 line, which is necessary for Eq. 7 to hold. To relate the emission intensities of the two remaining pairs of overlapping lines $(229.419 \& 229.787,337.494$ $\& 337.595$ ), it was assumed that upper states of the two lines ( 1 and 2) follow a Boltzmann distribution. ${ }^{15}$

$$
\frac{I_{1}}{I_{2}}=\frac{g_{1} A_{1} \lambda_{2}}{g_{2} A_{2} \lambda_{1}} \exp \left\{-\frac{E_{1}-E_{2}}{k T_{e}}\right\}
$$

Use of Eq. 8 to determine the intensity ratio necessitates an assignment of temperature, however the calculated intensities are insensitive to the choice in temperature for the range in which we are interested $(0.5-4 \mathrm{eV})$. While this relation may not rigorously hold, it does provide a reasonable first approximation. This allows us to simultaneously solve Eq. 6 and Eq. 7, or Eq. 6 and Eq. 8 to give us the 'resolved' intensities. In Fig. 7 we observe that the data for each species does not fall on a straight line; therefore an assignment of an electron temperature cannot be made with confidence. It should be noted however, that this does not necessarily mean that the plasma is not in LTE. This is because the acquired spectrum represents spatially and temporally integrated emission; the averages obtained may deviate systematically from the local and instantaneous values. While the spatially and temporally averaged spectra don't allow us to definitively state the value of the electron temperature, the data and the presence of doubly ionized gallium are consistent with a value of $T_{\mathrm{e}}$ in the $1-3 \mathrm{eV}$ range. 


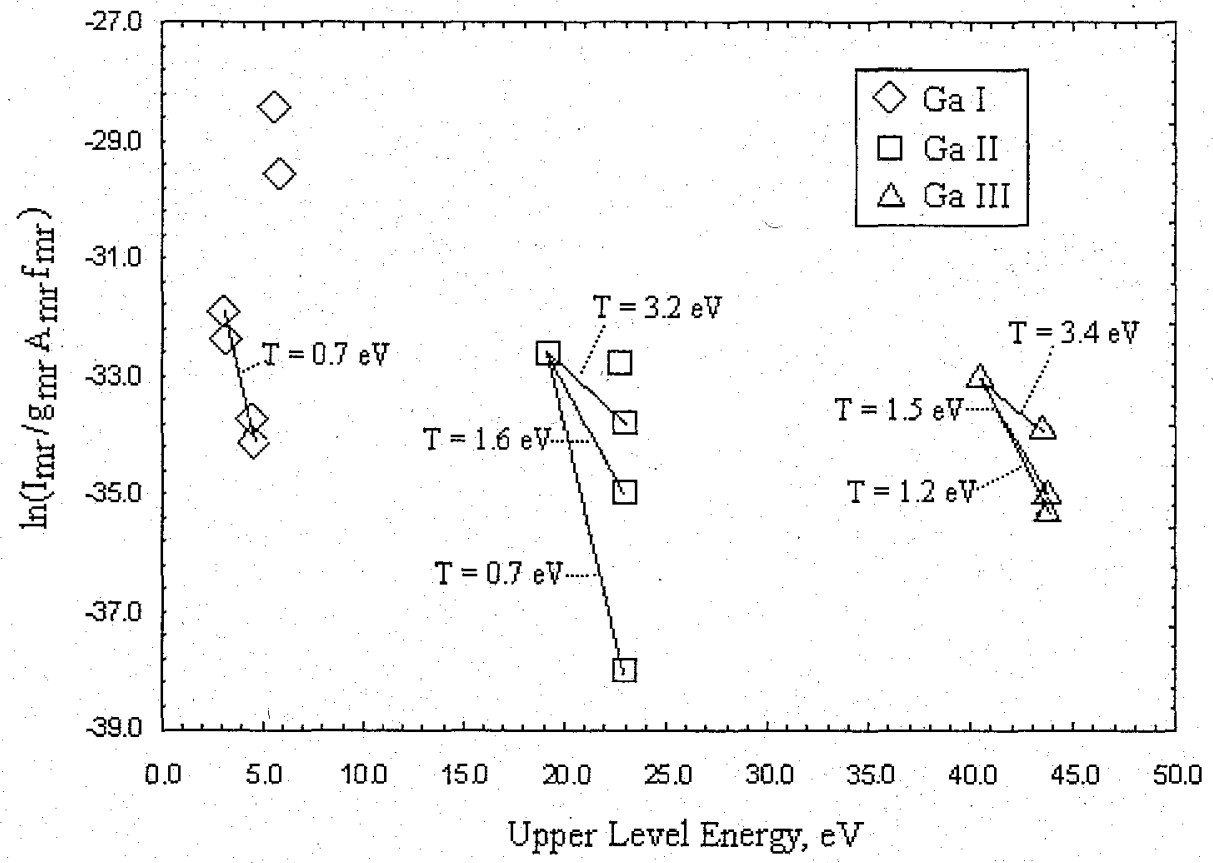

Figure 7. Boltzmann plots for gallium line emission data for a background pressure of 1 torr and an inner cathode diameter of $5 \mathrm{~mm}$.

\section{Conclusions}

As a propellant option for EMTs, gallium appears to have many advantages. It optimizes to reasonable discharge current levels and propellant mass flow rates for near-Earth missions requiring $I_{\text {sp }}$ between $1500-2000 \mathrm{~s}$. Photographs and spectroscopic data were acquired using a pulsed coaxial gallium plasma source operating at 20 $\mathrm{J} /$ pulse and yielding a peak current of $1.8 \mathrm{kA}$. Spectroscopic data were presented for two cases; one at a background pressure of 1 torr, and the other at a pressure of $5 \times 10^{-5}$ torr where a graphite bridge between the electrodes had to be employed to facilitate the breakdown process. We observed twenty $\mathrm{Ga}$ lines in the former case, owing to emission from neutral, singly, and doubly ionized particles. When the graphite layer was used, doubly ionized carbon was present in the discharge with molecular carbon radicals present in the emission spectrum above $430 \mathrm{~nm}$. Silicone rubber tape was used to cover the stainless steel portion of the electrode to ensure preferential arc attachment to the gallium. No significant traces of the insulator were found in the emission spectra from the plasma discharge. A relative emission line analysis shows that the acquired spatially and temporally averaged spectra don't fit well to a single electron temperature, but the data are consistent with $T_{\mathrm{e}}$ in the $1-3 \mathrm{eV}$ range.

\section{Acknowledgments}

The authors thank John Frus of GE/Unison Industries for support with the pulse-electronics.

\section{References}

${ }^{1}$ Markusic, T.E., Thio, Y.C.F., and Cassibry, J.T., "Design of a high-energy, two stage pulse plasma thruster," 38th AIAA/ASME/SAE/ASEE Joint Propulsion Conference, July 7-10, 2002, AIAA Paper 2002-4125.

${ }^{2}$ Polzin, K.A., Markusic, T.E., Burton, R.L., Thomas, R.E., and Carroll, D.L., "Gallium Electromagnetic (GEM) Thruster Concept and Design," 42 $2^{\text {nd }}$ ALAA/ASME/SAE/ASEE Joint Propulsion Conference, July 9-12, 2006, AIAA Paper 2006-4652.

${ }^{3}$ Choueiri E.Y, and Ziemer, J.K, "Quasi-Steady Magnetoplasmadynamic Thruster Performance Database, "J. Propulsion and Power, Vol 17,No. 5, 2001, pp. 967-976.

${ }^{4}$ Burton, R.L., Clark, K.E., and Jahn, R.G., "Measured Performance of a Multimegawatt MPD Thruster," J. Spacecraft, Vol. 20, No. 3, 1983, pp. 299-304. 
${ }^{5}$ Kim V.,V. Tikhonov, and S. Semenikhin, Fourth Quarterly (final) Report to NASA-JPL: 100-150 kW lithium thruster research, Technical Research, Contract No. NASW-4851, RAIME, MAI, Moscow, Russia, Apr. 1997.

${ }^{6}$ Anders, A., Brown, I.G., MacGill, R.A., and Dickenson, M.R., "Triggerless' Triggering of Vacuum Arcs," J. Phys. D: Appl. Phys., Vol. 31, 1998, pp. 584-587.

${ }^{7}$ Anders, A., Schein, J., and Qi, N., "Pulsed Vacuum-Arc Ion Source Operated with a "Triggerless" Arc Initiation Method," Rev. Sci. Instru., Vol 71, 2000, pp. 827-829.

${ }^{8}$ Martin, W.C., Fuhr, J.R., Kelleher, D.E., Musgrove, A., Podobedova, L., Reader, J., Saloman, E.B., Sansonetti, C.J., Wiese, W.L., Mohr, P.J., and Olsen, K. (1999). NIST Atomic Spectra Database (version 3.1.2), [Online]. Available: http://physics.nist.gov/asd [accessed May 25, 2007]. National Institute of Standards and Technology, Gaithersburg, MD.

${ }^{9}$ Isberg, B., and Litzen, U., "Revised and extended analysis of Ga II," Physica Scripta, Vol 31, 1985, pp. 533-538.

${ }^{10}$ Isberg, B., and Litzen, U., "Spectrum and term system of Copper-like Gallium, Ga III," Physica Scripta, Vol. 33, 1986, pp. 420-423.

${ }^{11}$ Castelli, F., and Parthasarathy, M., "Oscillator Strengths for Ultraviolet Ga II and Ga III Lines," Astronomical Society of the Pacific Conference Series, Vol 78, 1995, pp. 151-156.

${ }^{12}$ Nielsen, K., Karlsson, H., Wahlgren, G.M., "Analysis of the hyperfine and isotopic structure of Ga II in the optical spectrum of k Cnc and HR 7775," Aston. Astrophys. Vol. 363, 2000, pp. 815-820.

${ }^{13}$ Pearse, R.W.B., and Gaydon, A.G., The Identification of Molecular Spectra. Chapman and Hall, 1976, p. 82.

${ }^{14}$ Howatson, A.M., An Introduction to Gas Discharges, Pergamon Press, 1965, Chap. 8.

${ }^{15}$ Yalcin, S., Crosley, D.R., and Faris, G.W., "Influence of ambient conditions on the laser air spark," Appl. Phys. B., Vol 68, 1999, pp. 121-130.

${ }^{16}$ Griem, H.R., Plasina Spectroscopy, McGraw-Hill, 1964, Chap. 6 .

${ }^{17}$ Markusic, T.E., and Spores, R.A., "Spectroscopic Emission Measurements of a Pulsed Plasma Thruster Plume," $33^{\text {nd }}$ AIAA/ASME/SAE/ASEE Joint Propulsion Conference, July 6-9, 1997, AIAA Paper 1997-2924. 